ISSN: 2162-3104 Print/ ISSN: 2166-3750 Online

Volume 7, Issue 3 (2017), pp. 620-643

(C) Journal of International Students

http://jistudents.org/

doi: 10.5281/zenodo. 570025

\title{
International EFL/ESL Master Students' Adaptation Strategies for Academic Writing Practices at Tertiary Level
}

\author{
Manjet Kaur Mehar Singh \\ Universiti Sains Malaysia, Malaysia
}

\begin{abstract}
The present research provides insights into the different forms of adaptation strategies employed by international graduate students to overcome the challenges faced in the academic writing practices and gain access to their disciplinary communities of practice at Master's level. Qualitative data was collected through semi-structured in-depth focus group interviews. Respondents were 70 international graduate students enrolled in various Master-level programs. Semi-structured focus group interviews allowed the international graduate students to share their own experiences in the employment of suitable adaptation strategies to overcome the challenges faced in their academic writing practices in the Master programs. The adaptation strategies employed include enhancing their English language proficiency, referring to non-formal advisory services, and improving their academic writing style.
\end{abstract}

Keywords: academic writing practices; adaptation strategies; challenges; international graduate students; Master program

The crucial role of academic writing practices has been increasingly acknowledged in "integrating disparate ideas, synthesizing perspectives, and extending theory which demand a higher-level construction skills and perspective-taking, as well as greater concern for accuracy, voice, and audience” (Lavelle \& Bushrow, 2007, p. 809). The argument by Lavelle and Bushrow (2007) entails academic writing practices, as component of academic literacies, to be viewed as heterogeneous, diverse, contested social practices, shaped by interests and power relations, and are open to change (Starfield, 2007). These lead the student writers and their instructors to adopt different identities and positions in academic writing practices as they 
negotiate these contested practices, which construct meaning in a discipline rather than simply represent it. In the context of Master programs in any discipline, there is a general consensus among scholars, researchers, and teachers that academic writing is an essential component for many coursework assessments and it is critical that graduate students continuously develop their academic writing skills (Stevenson, 2006; Thomas, 2005; Wasley, 2008).

Currently, academic writing is also intricately related to a student's sense of self and identity. In fact, writing aids in both developing and demonstrating critical-thinking skills, and has been categorized as "the exterior sign of an interior thinking process” (Bean, 1996, p. 20). As a result of this, new graduate students have to identify themselves as part of a particular academic community, and without this identity formation, they will not be able to participate or acquire academic literacies skills linked to academic success.

In the context of graduate study, according to Casanave (2002), it is during the Master's degree where "the transition from novice to expert begins to take place” (p. 84). Similar to Casanave (2002), Braine (2002) in his argument noted that it is crucial for graduate students to build interactive and good relationships with their lecturers, thesis supervisors, and peers to ensure they gain entry to the discourse albeit as a legitimate peripheral participant, develop effective research strategies and good academic writing skills. However, there arise challenges in academic writing which have been documented by relevant studies (Elder \& Paul, 2006; Author, 2015; Ruggles, 2012). As highlighted by Elder and Paul (2006, p. 38), the academic writing process involved "intimate connection between the ability to write well and the ability to think well” and Ruggles's (2012) doctoral study had indicated that students are definitely struggling with the expectations of academic writing.

Subsequently, in the context of graduate study in Malaysia, this article contributes to the development of research focusing on international graduate students in the Asia-Pacific region. Most international students in Malaysian higher education institutions from the Middle Eastern and Arab countries such as Yemen, Iraq and Libya (Kassim, 2013; Pandian, Baboo \& Mahfoodh, 2014; Yusoff, 2012) have to use English in their academic activities (e.g. writing of assignments, writing of proposals, and writing their theses) as English language is the medium of academic communication for them. Therefore, they experience academic difficulties related to academic literacy, language skills, learning practices specific to host university settings, and learning unfamiliar academic conventions (Young \& Schartner, 2014). Research on these academic challenges or difficulties is gradually gaining interest among Malaysian researchers. However, research on international graduate students' adaptation strategies for academic writing 
practices in Malaysian context is limited. It is also crucial to understand the students' lived experiences in utilizing self-supporting strategies to overcome challenges in their academic writing practices is currently not specifically researched.

The main purpose of the present study is to obtain an insider's perspective of the adaptation strategies employed by the international EFL/ESL Master students to overcome the challenges faced in their academic writing practices especially in the process of gaining access to their academic disciplinary community. This purpose is considered crucial as the adaptation process is intricate and multifaceted.

\section{LITERATURE REVIEW}

At the global level, there is considerable research (Kaur \& Shakila, 2007; Kaur \& Sidhu, 2009; Lea \& Street, 2000; Leki, 2001) that focusses on academic writing at the undergraduate stage and dissertation writing at the doctoral level. However, critics such as Lavelle and Bushrow (2007) and Singleton-Jackson and Lumsden (2009), pointed that there is lack of research that looks into the academic writing process of Master students. For example, Lavelle and Bushrow (2007) emphasized that "little is known about what graduate students think about writing or about what they do when faced with academic writing tasks” (p. 816). Likewise, SingletonJackson and Lumsden (2009) indicated a "marked paucity in the research literature" on the writing proficiency of graduate students. Later, Fergie, Beeke, McKenna, and Crème (2011) had also observed that "much research into writing in higher education has taken undergraduate work as its subject, with rather less focus on postgraduate writing, although Ph.D. writers have attracted increasing attention more recently” (p. 237).

In the context of international students, Tran (2013) laid a strong emphasis that international students were being viewed from a deficit frame. The tenet of the deficit frame located international students' academic challenges as vastly sprouting exclusively from their cultural and linguistic backgrounds (Tran, 2013, p. 2). Tran also argued that students' agency, their adaptive capacity, and their transformative power issues lack research. Currently, it is observed that there is a lack of documentation in terms of intricate details involving the processes that these international students undergo to adapt to the academic culture of the disciplines that they are studying in. Students are assumed to independently and quickly acquire specific disciplinary knowledge when they enter graduate school.

In Malaysian context, the increasing number of incoming international students into its higher education institutions has brought linguistic, educational and cultural diversity (Carroll \& Ryan, 2005). The majority of these students are from English as Foreign Language (EFL) and English as Second Language (ESL) background. By accepting the 
international students, Malaysian higher education institutions have initiated the use of English language as the medium of instruction for academic programs involving them. However, the initiative undertaken by the Malaysian higher education institutions has backfired as the international graduate students with ESL and EFL language background lack English language proficiency.

Furthermore, research has found that one of the setbacks of lacking in English language proficiency is the negative impact on students' academic writing practices which had directly affected their academic success (Author, 2013; 2015; 2016). The notion of academic writing practices that students brought from their prior academic learning background at the undergraduate level differs from the similar notion and socialization in the current Master's community of practice. Their writing, which is affected by previous learning patterns, does not help them to quickly grasp the new and different academic expectations in graduate programs (Andrade, 2008; Campbell \& Li, 2008; Wong, 2004). Research also indicated that to become accustomed to an unfamiliar culture, a new education system and navigating these differences in a foreign language or second language (Andrade, 2008; Campbell \& Li, 2008; Mullen, 2006; Wong, 2004) is a lengthy process, difficult and stressful for graduate students.

In a past study on adaptation strategies, Yuchun (2010) noted that by working with other students, international students not only got the opportunity to share academic knowledge but also various learning strategies. It was also noted that their co-students were able to act as valuable learning resources. Concurrently, international students are able to improve their academic English skills, such as academic writing and progressively make adjustment to suit the expected style of academic writing as academic writing is crucial in determining their final grades. In Malaysia, the manner in which international EFL and ESL Master students accommodate, negotiate, and resist specific requirements and expectations embedded in particular disciplinary discourses remains unexplored. Furthermore, there is lack of availability of formal learning skills resources to support international students to develop their academic writing practices (Author, 2013).

Malaysian based research had also highlighted evidence that international graduate students in the universities struggled in reading and writing practices which are the thrust of academic literacies (Kaur \& Shakila, 2007; Kaur \& Sidhu, 2009). Concurrently, Ibrahim and Nambiar (2011) identified that the students' experiences at their home country where they had obtained their first degree (bachelor's degree) did not prepare them for the rigors of writing project papers in their present university located in a foreign country. The respondents in Ibrahim and Nambiar's study claimed 
that there were differences in teaching and learning styles between the higher education institution in Malaysia and their home countries. Furthermore, the respondents stated that they were not prepared for the autonomy presented in the process of writing their academic papers. In addition, the respondents, who were postgraduate students reported that cross-cultural limitations stemming from differences in teaching and learning styles within the Malaysian higher education institutions and their home countries did not positively contribute toward the progress of their academic writing practices (Ibrahim \& Nambiar, 2011).

In addition, Author's (2016) qualitative study to determine the challenges faced by international graduate students in their academic writing practices indicated difficulty in adhering to proper academic writing techniques. Furthermore, the students' prior academic cultural background and lack of English language proficiency were obstacles faced by the students. At the same time, due to communication hurdles, the students also faced difficulty in obtaining corrective feedback on their academic work from their lectures. In the context of recommendations on how to overcome the challenges in academic writing practices, Author (2016) provided recommendations to the stakeholders such as the lecturers and the management body of universities to address the challenges faced by the international graduate students in their academic writing practices. However, the students' perspectives on their role in overcoming the challenges faced in academic writing practices which is the core of this study have not been investigated in research.

The argument provided by Brown (2008a; 2008b) and Kaur (2000) were also cited in earlier research by Conrad, Duren and Haworth (1998), Green (1987), and Stewart and Spille (1988). These scholars claim that there is extremely limited literature on how students experience their Master programs, much less the effects of their experience on students themselves. In addition, literature also does not draw on students' perspectives. Research has also been anchored mostly in the voices of faculty and administrators. Furthermore, graduate study is the means by which learners join the professional ranks of their disciplines, claiming authority within academic departments and by extension, gaining access to personal, social, political, and economic privileges. Hence, graduate students are likely to be more highly aware of and concerned for their own disciplinary enculturation than undergraduates (Belcher, 1989).

To conclude, although there is a relevant body of studies on academic writing practices among international students, the review of literature shows that no previous qualitative studies were conducted on the adaptation strategies employed by the international graduate students to overcome the challenges in academic writing practices in Malaysian higher education institutions. In line with these inadequacies, the current study only 
provides non-Malaysian based literature on adaptation strategies employed by international graduate students to overcome the challenges faced in academic writing practices.

\section{THEORETICAL FRAMEWORK}

Two theoretical approaches guided the current study are indicated in the conceptual framework (Figure 1). The theoretical approaches are the Academic Literacies Model (Lea \& Street, 1998, 2000; Lillis \& Scott, 2007), and the Discipline Enculturation into Community of Practice (CoP) (Lave \& Wenger, 1991).

\section{Academic Literacies Model (ALM)}

Academic Literacies Model (ALM) which originated from the social and ideological orientation of the New Literacies Studies (Lea \& Street, 1998; Lea \& Street, 2006; Street, 1984) attempts to understand how students negotiate and make sense of academic learning as they become effective members of academic discourse communities. These scholars also claimed that ALM treated writing as a social practice that varies across context (discourses of institutions within the academic culture) (Lea \& Street, 2000). ALM also focuses on academic writing practices from the perspective of the students rather than the educators. This new pedagogical direction according to Leki (2001) was to shift the focus away from the educator's perspective of literacy to the students as it gave more voice to the students.

One of the fundamental characteristics of academic literacies discourse is that it gives recognition to the language repertoires and literacy practices that students bring with them into higher education and the need to guide the students to develop their awareness of what is appropriate to a given setting (Preece, 2010). In terms of academic writing practices, these diverse literacy practices indicate that successful meaning making possibly results from students' negotiated and collaborative efforts to align their academic writing practices to the expected practices in their current educational institution. Additionally, Braine (2002) stated that academic literacies reflected content, knowledge, study skills and the socio-cultural aspects of being a student in a particular academic community.

\section{Discipline Enculturation into Community of Practice (CoP)}

Learning is viewed as a situated activity in a community of practice (CoP) which highlights the mastery of knowledge and skills required by a novice to gradually move towards full participation in the socio-cultural practices of a community. CoP has as its core a process called legitimate peripheral participation (Lave \& Wenger, 1991). Lave and Wenger base students' identification as members of the academic community on their 
participation in the academic community and this should occur throughout the duration of the academic program which students are enrolled in (Lave \& Wenger, 1991). Flowerdew (2000) further added that it was within the discourse communities that novice scholars who were legitimate peripheral participants as newcomers to a CoP become inducted into their disciplinary communities through various forms of apprenticeship.

In addition, earlier studies by Leki and Carson (1994), Norton and Starfield (1997), and Prior (1994) pointed out that classroom activities are crucial elements in disciplinary enculturation. These activities that induct students into a particular discipline such as lectures, oral work, laboratory work, doing reading, lecturers' feedback, and especially writing through which the success of academic performance is decided. Those studies reported that by getting involved in these activities, a learner learned a kind of language that is used to facilitate his/her interactions through academic discourse with other academic community members.

\section{Figure 1. Theoretical Framework}

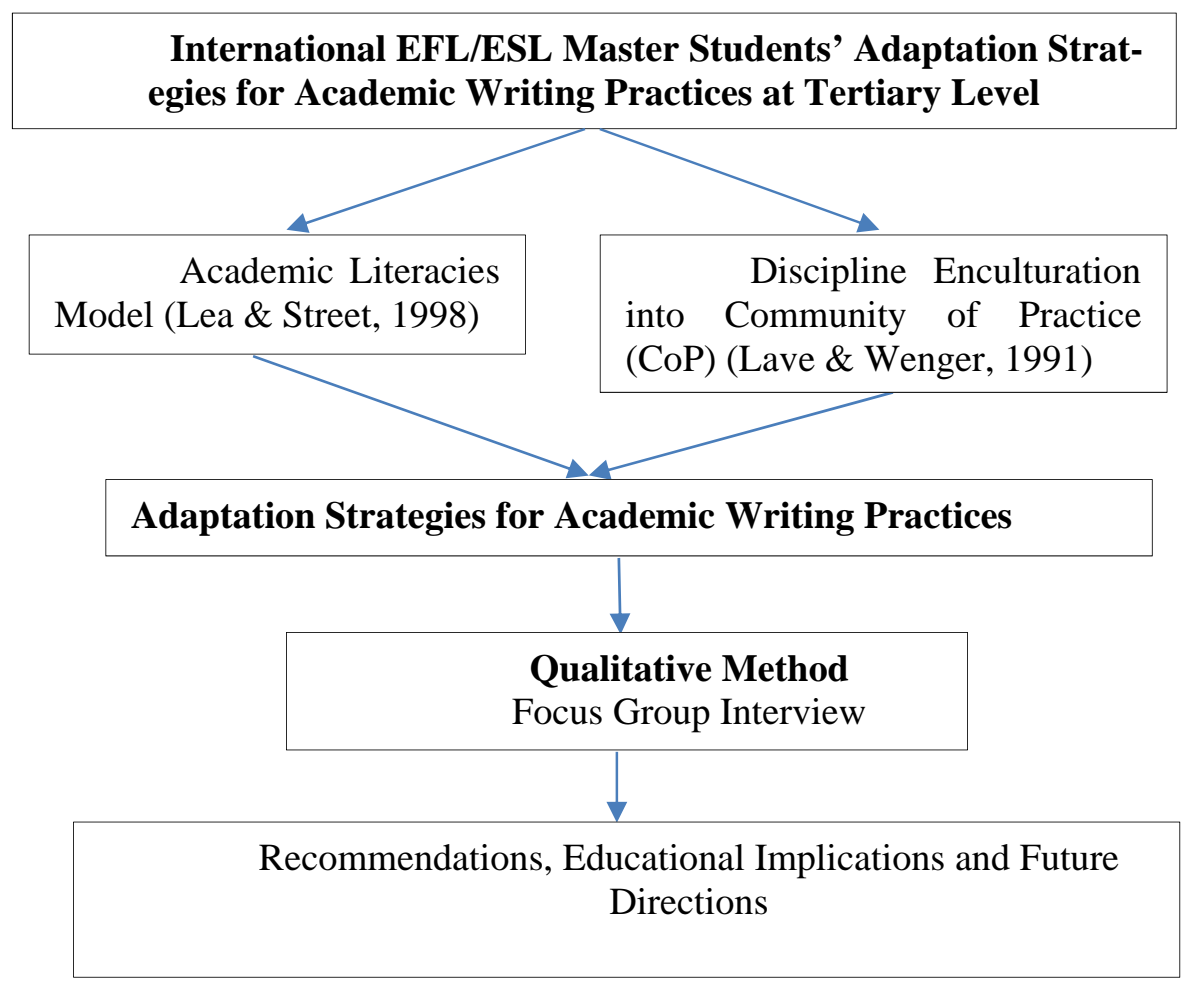




\section{RESEARCH METHOD}

\section{Research Design}

The study focused on the adaptation strategies employed by international graduate students in Master programs to overcome the challenges in their academic writing practices. A basic interpretive qualitative study focusing on insider's perspectives (Burke \& Wyatt-Smith, 1996) was carried out. This involved in-depth focus group interviews (FGI). The rationale behind this approach is that semi structured in-depth focus group interviews allowed for the extraction of detailed and reliable perspectives on the adaptation strategies employed by the international graduate students.

\section{Population}

The target population of this study was international graduate students in the Master programs in a higher education institution in Malaysia. This study utilized purposive sampling with the aim of selecting all accessible respondents who could provide accurate and reliable information regarding the research problem. This is because purposive sampling involves selecting a sample that yields the most comprehensive understanding in the form of rich information on the topic. According to Creswell (1998) and Creswell and Plano Clark (2007), purposive sampling ensures that only those respondents who can make a meaningful contribution to the research are included in the study. In addition, purposive sampling also comprises elements that contain the most representative qualities of the population (Fraenkel \& Wallen, 2008; Patton, 2008; Rubin \& Babbie, 2009).

Data obtained from The Institute of Postgraduate Studies (IPS) indicated there were 203 full time international students registered for the second semester in the Master programs offered at the 10 faculties. These faculties comprise of three Arts, two Hybrid and five Sciences. The students have completed their undergraduate study, thus, being familiar with tertiary institution's academic writing practices. The students had also acquired discipline content knowledge at the first-degree level. Finally, they have had exposure to academic literacies (writing, reading, listening and speaking) of graduate study during their first semester in the Master programs.

The justification of selecting students from the coursework Master programs is because these students are exposed to a variety of academic writing practices compared to their counterparts in the research programs. A large portion of the learning in these Master programs is facilitated through classroom lectures, tutorials, seminars, individual project work, industrial or business placement, problem-solving classes, group projects, 
research dissertation or discussion groups (Brown, 2008a; 2008b; Kaur, 2000 ) that requires a considerable amount of academic writing output.

International graduate students' participation in the study was on voluntary basis. The students were provided an overview of the study. Then, their consent was obtained via a consent form. This method of obtaining respondents on a voluntary basis follows what Spradley and McCurdy (1972) view as a good informant, "one who knows the culture well, is willing to talk and is non-analytical in communicating his/her world” (p. 47).

The 70 respondents (Table. 1) who voluntarily took part in the FGIs were coded according to a number provided to each respondent and a letter used to identify their faculty. Pseudonyms were applied to ensure anonymity of the respondents and confidentiality of data related to particular respondents. This was done by creating a coding scheme for coding purposes. For example, a respondent who responded in the interview session from a particular faculty is coded as $2 A$. The symbol 2 represents the respondent's number and $A$ represents the student's faculty's code.

\section{Table 1. Coding of FGI Respondents $(\mathrm{N}=70)$}

\begin{tabular}{lll}
\hline Faculty - Arts) & (Faculty - Hybrid) & (Faculty Science) \\
19 respondents & 20 respondents & 31 respondents
\end{tabular}

\section{Profile of the Respondents}

There is a blend of many nationalities among the respondents ranging from the Middle East, Asian and African countries. Majority of the respondents are from the Middle East countries. Iran has the highest number of respondents, followed by Iraq, Palestine, Libya, Yemen, Jordan, Saudi Arabia and Egypt. A minority of the respondents are from other Asian and African countries.

The primary language used for lecture purposes during the student's first-degree is English language. A small number of the respondents from the Middle East countries used Persian and Arabic language during their first-degree's study. The language that was most frequently used for discussion with lecturers was English language. The respondents from the Middle East countries also preferred to use Arabic and Persian for discussions in their first degree. The respondents from China used a combination of English and Chinese or only Chinese language in their first degree's study.

Majority of the respondents used English language as the main language for writing task during their undergraduate study. English was followed by Persian, Arabic and Chinese language. Likewise, the English language was the most frequently used for reading material purposes. The 
respondents from the Middle East countries used Persian language. A minority of the respondents used Arabic. Only a small number of respondents from China read in English.

\section{Focus Group Interviews (FGI)}

The primary qualitative data gathering technique used for this study is the FGI. Focus group is a group interview that depends on a questionand-answer format (Krueger \& Casey, 2000) and the researcher is actively encouraging and attentive to the group interaction (Kitzinger \& Barbour, 1999). This approach of collecting qualitative data is based on the assumption that people are an important source of information about themselves, their experiences, knowledge, opinion, beliefs, feelings, and the issue that affect their lives and they can articulate their thoughts and feelings (Best \& Kahn, 2006).

The synergistic group effect (Stewart \& Shandasani, 1990) provided information that individual interviews could not achieve as respondents' behaviors and attitudes are not made individually in isolation but in a social context. Furthermore, Morgan (1988), Stewart \& Shamdasani (1990) and Krueger (1994) added that this data collection method is more advantageous when the interaction among interviewees will likely to produce the best information; when interviewees are similar and cooperative with each other; when the time to gather information is restricted. However, if the respondents were interviewed individually, they may be hesitant to provide information. In addition, this method was also able to reduce the influence and role of the researcher (Vanderstoep \& Johnston, 2009).

Table 2. Categories of Questions (Krueger, 1998)

\section{Question Purpose}

Opening Participants get acquainted and feel connected

Introductory Begins discussion of topic

Transition Moves smoothly and seamlessly into key questions

Key Obtains insight on areas of central concern in the study

Ending Helps researcher determine where to place emphasis and brings closure to the discussion

The research utilized a mixed type of focus group known as Type 8. Type 8 focus group includes questions that are both open and close-ended (Johnson \& Turner, 2003). The literature in the area of academic writing practices among graduate students guided the design of questions for the FGI. Questioning was done in systematic and consistent manner and the researcher probed far beyond the responses offered to the prepared questions 
(Berg, 2004). Krueger's categories of questions (1998) (Table. 2) and Krueger's (1994) (Table. 3) focus group data collection flow chart guided the present study.

Table 3. Data collection flow chart of FGI adapted from Krueger (1994)

\begin{tabular}{l|l}
\hline $\begin{array}{l}\text { Data Collection Flow } \\
\text { Chart of the FGI }\end{array}$ & Description \\
\hline 1. Sequencing of questions & $\begin{array}{l}\text { Opening questions, introductory questions, } \\
\text { transition questions, key questions, ending } \\
\text { questions. }\end{array}$ \\
\hline $\begin{array}{l}\text { 2. Capturing and handling } \\
\text { data }\end{array}$ & Audio-taping, field journal notes of researcher \\
\hline 3.Coding of data & $\begin{array}{l}\text { Placing codes in the margin of the interview } \\
\text { transcript }\end{array}$ \\
\hline 4.Member Checking & $\begin{array}{l}\text { Emailing the transcript to the FGI respondents } \\
\text { for member checking. }\end{array}$ \\
\hline
\end{tabular}

Seventeen (17) interview groups within the range of three to seven respondents per group were formed. The number of respondents per group is in line with Kruger's (1994) "rule of thumb", which stated that a focus group should not comprise less than three respondents and should not be more than seven participants. Mainly, the 17 interview groups comprised of four to five respondents. The FGI sessions were held at various dates, times and venues at the research site university that was convenient to the 70 respondents who volunteered to take part in the FGI. Each interview session lasted between 40 minutes to one hour.

\section{Table 4. Interview Guide/Protocol}

Interview Guide/Protocol

1. How do you go about writing an essay? Tell me about your writing process. Where do you usually write? How do you write? Do you get help from others (friends, lecturers, writing center)? How well can you do them?

2. How do you feel about writing? In English? In your native language?

3. What difficulties do you face in the writing you do for your course?

4. What measures do you apply to help you overcome the difficulties you face in writing?

5. What kind of support would you have liked in completing the assignments?

Focus group interviews, which were conducted in English language, were audio taped and transcribed by the researcher at the end of each interview session to derive the qualitative data. An interview guide/protocol 
that focused on the adaptation strategies employed by respondents in overcoming the challenges in their academic writing practices was used as a reference to facilitate the interviews. At the same time, the respondents were given the opportunity to discuss relevant arising issues and concerns. The interview guide/protocol used in the research is provided in Table 4 below.

\section{Data Analysis}

The researcher used Microsoft Word compatible qualitative research data analysis software, NVivo 10 to organize and analyze complex data and emerging patterns extracted from the transcription. According to Miles and Huberman (1994) and Braun and Clarke (2006), NVivo 10 is useful for researchers in moving data easily from one code to another and to document the data as it is analyzed. The use of the software increased the validity of the data analyzed.

Data analysis involved five phases involving familiarizing with the data, generating intial codes, searching for themes, reviewieng themes, defining and naming themes and finally, producing the report (Braun \& Clarke, 2006; Creswell \& Plano Clark, 2007). The core feature of the qualitative data analysis of this research was coding. The coding of the data was done using thematic analysis, a qualitative analytic method explained by Braun \& Clarke (2006) as identifying, analysing, and reporting patterns (themes) within data. It organizes, describes the data set in detail and interprets various aspects of the research topic (Braun \& Clarke, 2006, p.79). Evidence from the various databases was grouped into codes and codes were grouped into broader themes (Braun \& Clarke, 2006, p. 82). The themes that captured the relevant data from the interview transcripts to answer the research question and represent the patterned responses within the data set were created.

\section{RESULTS}

This section focuses on the international EFL/ESL Master students' adaptation strategies for overcoming the challenges in their academic writing practices. The following adaptation strategies identified are multipronged and the respondents opted for different forms of strategies for different expectations.

Table 5: Adaptation Strategies for Overcoming the Challenges in Academic Writing Practices

Adaptation Strategies for Overcoming the Challenges in Academic Writing Practices

1. employing correct writing techniques

2. utilizing external resources to assist in their writing

3. referring to non-formal advisory service

4. enhancing English language proficiency 


\section{Employing correct writing techniques}

In the process of writing assignments, project reports and dissertations, most of the respondents indicated that they struggled to shift from their former habit of writing to the new expectations in the Master programs. The respondents tried to align their writing to the expectations set in terms of academic writing by their lecturers. The respondents emphasized that employing correct writing techniques involved doing a lot of practices consistently to produce good academic work. Moreover, the respondents indicated that this strategy helped them in selecting the suitable or correct vocabulary, writing grammatically correct sentences, and adhering to academic writing protocol. Five respondents agreed that a lot of practice in writing in English was crucial as English is a foreign language for them.

I can confess that my writing is better than the day that I came here because we practiced a lot of writing. [S2B]

Apart from employing suitable writing techniques, a Chinese respondent indicated that he would write his draft in his native language and then translate it into English either manually or with the assistance of the Google Translator. However, the respondent faced challenges in manual editing of the academic work translated via Google Translator as the translated version's language and content accuracy was doubtful. Nevertheless, the respondent still concentrated his effort in rectifying the grammatical errors with the help of his prior/background grammar rules knowledge. Another Thai respondent remarked that strategies such as using simple words and expanding assignments based on lecture notes were effective.

first thing I read... the in Thai language first from the article, from other lecturer, what is the abstract mean, how to write the abstract... and after that I find some... some journal or some slide to see what ... how to write in English. Like that and I try to write by myself [S4E]

In addition, another respondent also added that her friends and she referred to completed academic work (assignments and articles) to obtain more ideas on the style of academic writing. At the same time, most of the respondents emphasized that they integrated the copied and pasted information from various sources in order to produce their own writing.

Researcher: So, what do you do, you take from here, here, there then you combine? Isn't take plagiarism? 
S3D: That's not plagiarism

S4D: You paraphrasing. Good article you take some point to refer as reference but you not take as as as whole.

Researcher: As a whole.

S3D: Yes. [S3D and S4D]

Six respondents from various faculties stated that by reading related articles and dissertations helped them in improving the writing style of their assignments. At the same time, one of the respondents had strong belief that this strategy helped to provide information on the accepted style of writing using the American Psychological Association (APA) guidelines. Subsequently, another respondent found that the strategy helped to eliminate the difficulties of paraphrasing and quoting others' work.

I try to read more articles and more articles and see how they write the ... for example discussion, conclusion which you ...words they use and in these way I try to learn. [3J]

Another respondent added that the process of completing many assignments throughout his Master program provided him an insider's view of the initial steps of writing papers, proposals, introduction section and statement of problem's section. In addition, another strategy found useful by the international students is memorizing. A majority of the respondents read and memorized words relevant to their discipline/field and then used them in their writing. Apart from that, respondent, S7G did vocabulary search to choose the most suitable vocabulary to construct the sentences. An example given by an Indonesian respondent is sourcing references in Bahasa Indonesia (Indonesian language) for further reading on the topic before starting her assignment. Subsequently, the respondent continued to read the English reading references to guide her writing.

I'm trying to write the right vocabulary and search about which one is the better for write for science exactly. That's how am I settle this problem. [S7G]

\section{Utilizing external resources to assist in their writing}

External resources such as the use of dictionary also assisted the students in their writing. Four respondents stated that they referred to the dictionary when writing in English language as it was very useful. S8E added that the daily use of dictionary helped him learn new words. The respondent emphasized that the use of either offline or online dictionary should be utilized to assist in the students' progress as it is also a significant adaptation strategy in improving students' academic writing practices. 
S10G referred to online dictionary to help her in her writing. Two respondents from the Arts and three from the Sciences also mentioned that they referred to various search engines such as Google Scholar to improve their writing and obtain information. S1B stated that students' academic writing practices can be improved by surfing relevant websites for additional information. For example, by reading sample proposals and sample dissertations, students can learn the art of academic writing.

The respondents (S5C and S2I) in the focus group interviews pointed out that they used search engines such as Google to download similar research as theirs as guidance to improve their academic writing in terms of idea, structure and vocabulary usage. Moreover, S4B also stated that joining a Facebook group has helped her communicate with her course mates and ease the challenges faced in her academic writing. In addition, S8E stated that she used the Google Translator to correct her language errors and prayed that the lecturers would be able to read and understand her writing.

...for correcting my mistake inside my essay I use Google translator and after that I pray they can understand or can read my essay. [S8E]

Two respondents from a Hybrid school added knowing the existence of Postgraduate Academic Support Services (PASS) at the Institute of Postgraduate Studies (IPS) in their university and desired to use the services offered such as the professional development workshops for students. However, the respondents argued that they did not have the chance to attend the relevant workshops and talks. Two of the reasons cited by S4E are the clashes of time between the workshops organized by PASS and their lecture hours. The respondents also faced time constraint in attending the workshops as they had many assignments to complete. On the other hand, some of the respondents such as S1C were not aware of the existence of the services offered to graduate students.

Most of the respondents also sent their thesis to paid professional editors for language editing. In addition, respondents who could not afford to pay high fees of professional editors sent their thesis to language editors at PASS. However, S3A and S3J added that the existing number of professional editors at PASS could not accommodate the number of graduate students who needed language help with their academic writing.

...you should go there before the exam, because near end of the semester everybody is going there get very crowded and they going to give your essay back maybe one month after you giving them [S3A] 
At the same time, some students, for example, S4B used the avenue of academic conferences and seminars to interact with the renowned presenters to obtain discipline content knowledge to assist in their writing. According to S3G and S2D, sitting for English language professional examinations such as IELTS also assisted students to overcome their challenges in academic writing practices.

I try to force myself to take the IELTS exam. By myself. I think I used the exam... in the previous time...limited time and do it. Okay, I think it helped me a lot. Yeah, for the improvement of the writing. [S2D]

\section{Referring to Non-Formal Advisory Services}

The analysis of the focus group interviews also revealed that the respondents' seniors and friends in graduate programs, family members and lecturers provided guidance and assistance in their academic writing practices. Nine respondents stated that they normally requested assistance from other international friends in their graduate programs. The coaching and feedback obtained helped improve their writing ability. Alternatively, S3G's spouse, a $\mathrm{PhD}$ candidate helped her husband in his writing.

Actually my wife is a $\mathrm{PhD}$ student in literature English, she helped me a lot but sometimes I was very pressured because I know what I want to say but I can't write that in exams, it is very bad. [S3G]

My friend give me some topic and I got to write some essay and after that I give him... he check the grammar and some mistake. Its a good way for improve your writing. [S9G]

Three respondents stated that they were helped by their relatives such as their father, brother and uncle. Respondent S10G was assisted by her brother in the process of her thesis writing (in correcting her grammar and paraphrasing to avoid plagiarism) as he was more experienced. According to S1G, her uncle who has a $\mathrm{PhD}$ helped her to improve her writing by doing regular writing practice outside classroom.

Actually he gives me--- It's general topics that he gives me and asks me to just write and then he come and corrects it for me. [S1G]

Three respondents mentioned that they also approached lecturers for guidance on writing techniques. Lecturers were considered as a source of guidance, feedback and a source of information and knowledge. According to S1A, she sometimes approached the lecturers to find out whether she was 
on the right track in her writing. S1A stated she did multiple drafts of assignments and got feedback from the lecturers. Similarly, S3B highlighted that lecturers were the only source of guidance for her to learn the conventions and regulations of her discipline. Her course mate, S2B, cited lecturers as the source of information and knowledge.

\section{Enhancing English language proficiency}

The respondents in the focus group interviews pointed that enhancing English language proficiency before enrolling in a graduate program is important if students want to have a good head start in their studies. Respondent, S8E suggested enrolling in English language improvement programs such as at British Council or their higher education institution's intensive English language programs. Another alternative provided by respondent, S3G was to listen to spoken English language via videos uploaded on YouTube to improve one's proficiency. This would assist in their writing. Furthermore, respondent S3G indicated reading transcript of oral conversations from specific websites helped him improve his English language proficiency.

\section{DISCUSSION}

The findings above provide specific instances whereby the students adapted to the new ways of academic writing practices expected in the Malaysian academic context and empowered themselves in the endeavor to fit in the present institutional structure. The adaptation strategies employed by the students are multi-faceted and add a multi-layer influence on the success of their academic writing practices. Consequently, the findings have given insights from the students' perspective on how they faced the challenges in their academic writing practices. The findings provide an avenue for a more expansive understanding of academic writing that recognizes value in linguistic and cultural diversity of international graduate students in target English language academic communities.

The discussion of the adaptation strategies (employing correct writing techniques, utilizing external resources to assist in their writing, referring to non-formal advisory service, and enhancing English language proficiency) employed by the students can be categorized into four concepts of adaptation that are surface adaptation, committed adaptation, reverse adaptation and hybrid adaptation as propagated by Tran (2013).

Committed adaptation occurs when students accomodate or comply to what is required by the institution. The students learnt new ways of constructing knowledge by struggling to shift from their former habit of writing to the new ways expected in their disciplines in Malaysia. The students tried to accommodate what was expected in terms of academic writing practices in their new learning environment at the graduate level. 
Hence, when confronted with different ideas about academic writing in their discipline, they shifted their former belief and negotiated ways of writing in light of the new belief in an attempt to satisfy the lecturers' expectations and take control of their own academic practices. It also influenced their awareness of the academic writing requirements in their discipline. These students managed to adapt to the ways of writing which are accepted in the Malaysian higher education institutions.

These students also enacted surface adaptation by shifting their former beliefs and negotiating ways of writing based on new beliefs imposed by the institutions' expectations. As indicated by Tran (2013), this kind of adaptation refers to the surface changes the students make in order to enable them to gain access to the conventions, which prevail in their academic discipline. Students also integrated their adaptation strategies to overcome the challenges in order to derive at hybrid adaptation. In this particular form adaptation, students treat their first language and culture more as a resource rather than a problem. The findings indicate that students have resorted to translating academic work in English language into their L1 for reference and producing new academic work in English language based on their understanding in L1 source.

A clear change in how the students write can also be analyzed through reverse adaptation. Based on the adaptation strategies under the theme of utilizing external resources to assist in their writing and referring to non-formal advisory service, the students have successfully created a positive change in their initial habit of writing in their L1 and translating into English language. Expanding the lens of looking at the adaptation strategies employed by the students, Siti and Hamidah (2014) in a study involving academic adaptation of Malaysian postgraduate students in Australia indicated that one of the strategies used by the postgraduate students was being more optimistic regarding their academic achievement. This may be due to them being pressured to excel in their academic life and complete their study within the time frame as they were scholarship funded students. The findings are consistent with the current study whereby the students show optimism by seeking support and advice from their friends, family members (for e.g. spouse) and lecturers. The students not only obtain academic advice from those close to them, but also receive motivation to improve their academic writing practices.

At the same time, the university's administration needs to look into providing support through proper and official channels to international students. At present, the research site university is aggressively marketing its academic programs and recruiting international students. However, the university lacks sustainability in terms of providing academic support necessary to the international graduate students who come from a different cultural context to survive in a new academic environment. Although 
Malaysia is attractive to many students with similar race, religion and cultural values, it does not support the expectation of academic culture of the universities that are very British oriented. As suggested by Ryan (2000, p. 5), "universities need to respond to the needs of international students by opening not just their doors for them, but once in, making sure that the curriculum is also accessible".

\section{RECOMMENDATIONS}

International Master's students as novice writers and researchers must be enculturated into the academic community especially integrating with the expected culture of academic writing. This initiative needs intensive responsibility on behalf of the university in assisting the students to develop critical writing skills. The first initiative involves the designing of writing programs as indicated by McCallister (2004). The existence of such a program will provide great assistance to the international graduates who need to be exposed the graduate level academic writing style and at the same time overcome the lack of their English language proficiency. The knowledge transfer of these programs into Malaysian academic writing culture can showcase a curriculum that approaches writing as a social and cognitive process to "position the students squarely in the midst of the world of things, ideas, history, and people and invite them to use writing as a means to participate in that world” (McCallister, 2004, p. 145).

Secondly, the importance of constructive feedback should be encouraged among lecturers to ensure they responsibly read and critique drafts, as well as recommend or even help the students obtain relevant materials (e.g., sources, references, databases). This is very crucial as intermittent feedback as a source of improvement in student writing is lacking among lecturers. Another effort is scaffolding assisted learning grounded in constructivist psychological theory. Assisted learning grounded in constructivist psychological theory entails mastery learning, faculty mentoring, and scaffolding. In this kind of assisted learning, lecturers will have the opportunity to provide support that students need to learn how to perform a task effectively (Mullen, 2006). Gradually, with the students' successful enculturation into their academic community, the students will be able to use their knowledge, skill and disposition to carry out their academic writing task independently.

Lecturers also need to ensure that their expectations are more explicit to the students. Apart from that, the lecturers should engage themselves to have more insights into the students' challenges as well as their values. These steps will contribute in ensuring reciprocal adaptation which entails reciprocal relationships between students and the academics and the enhancement of the inclusive practices of the students' host 
institution (Tran, 2013). Indirectly, this will reduce the intensity of mismatch between the lecturers' expectations and students' display of disciplinary knowledge. This involves international graduate students adapting to the local academic requirements. It also involves teachers attempting to modify their teaching approaches in response to the changing needs of the relevant student population for sustainable academic development as suggested by Tran (2008). Improvement in the international graduate students' educational experience has the potential to create a reputation of student driven higher education agenda among higher education institutions in Malaysia.

\section{CONCLUSION}

This study has revealed how international EFL/ESL Master students who come from different academic literacy backgrounds and differ from the present institutionally accepted codes and conventions faced the challenges in their academic writing practices and use adaptation strategies to overcome the challenges. The higher education institutions of Malaysia, which are on a serious quest to upgrade the education system to international standards and join the global ranking as a provider of tertiary education for the international society, should work towards ensuring a positive learning experience for international students. The universities should be committed to rethinking what counts as quality in teaching and learning and to implement policies to ensure successful engagement of the students in their academic community.

Nevertheless, this study is also not without any limitations. The findings present only a small part of a much larger picture of the academic endeavor especially the academic writing experience of the students within a broader context of their past and present cultural, linguistic, and educational experiences. In addition, this study only focused on international students at Master level and only in one Malaysian public university. Further study should focus on international undergraduate, doctorate and Master students in more universities to identify the distinction in their academic writing adaptation strategies.

\section{REFERENCES}

Andrade, M.S. (2008). International graduate students: Adjusting to study in the United States. In Tokuno, K.A. (Eds.), Graduate Students in Transition: Assisting Students through First Year. No. 50 (pp. 71- 90). University of South California, South California.

Bean, J. C. (1996). Engaging ideas: The professor's guide to integrating writing, critical thinking and active learning in the classroom. San Francisco, CA: Jossey-Bass. 
Belcher, D. (1989). How professors initiate nonnative speakers into their disciplinary discourse communities. Texas Papers in Foreign Language Education, 1 (3), 207- 225.

Berg, B.L. (2004). Qualitative research methods for the social sciences. (5 ${ }^{\text {th }}$ Ed.). Boston, MA: Pearson.

Best, J. W., \& Kahn, J.V. (2006). Research in Education (10 ${ }^{\text {th }}$ Ed.). Boston, MA: Pearson.

Braine, G. (2002). Academic literacy and nonnative speaker graduate student. Journal of English for academic purposes, 1(1), 59-68.

Braun, V., \& Clarke, V. (2006). Using thematic analysis in psychology. Qualitative Research in Psychology, 3(2), 77-101.

Brown, L. (2008a). the incidence of study-related stress in international students in the initial stage of the international sojourn. Journal of Studies in International Education, 12(1), 5-28.

Brown, L. (2008b). Language and Anxiety: An ethnographic study of international postgraduate students. Evaluation \& Research in Education, 21(2), 75-95.

Burke, E., \& Wyatt-Smith, C. (1996). Academic and non-academic difficulties: perceptions of graduate non-english speaking background students. TESL-EJ, 2(1), 23-54.

Campbell, J., \& Li, M. (2008). Asian students’ voices: an empirical study of Asian students' learning experiences at a New Zealand university. Journal of Studies in International Education, 12(4), 375-396.

Carroll, J., \& Ryan, J. (2005). Teaching international students: Improving learning for all. Abingdon, UK: Routledge.

Casanave, C.P. (2002). Writing games: Multicultural case studies of academic literacy practices in higher education. Mahwah, NJ: Erlbaum.

Conrad, C.F., Duren, K.M., \& Hawoth, J.G. (1998). Students’ perspectives on their master's degree experiences: Disturbing the conventional wisdom. New Directions in Higher Education. 101,456-459.

Creswell, J.W. (1998). Qualitative inquiry and research design: Choosing among the five traditions. Thousand Oaks, CA: Sage Publications.

Creswell, J. \& Plano Clark, V. (2007). Designing and conducting mixed methods research. Thousand Oaks, CA: Sage.

Elder, L., \& Paul, R. (2006). The miniature guide to the art of asking essential questions. Dillon Beach, CA: Foundation for Critical Thinking.

Fraenkel, J. R., \& Wallen, N.E. (2008). How to Design and Evaluate Research in Education. ( $7^{\text {th }}$ ed.). New York: McGraw-Hill International Edition.

Fergie, G., Beeke, S., McKenna, C., \& Crème, P. (2011). It’s a lonely walk: supporting postgraduate researchers through writing. International Journal of Teaching and Learning in Higher Education, 23(2), 236-245.

Flowerdew, J. (2000). Discourse community, legitimate peripheral participation, and the non-native English speaking scholar. TESOL Quarterly, 34(1), 127 $-148$.

Green, J. L. (Ed.). (1987). The master's degree: Jack of all trades. Denver, CO: State Higher Education Executive Officers.

Johnson, B., \& Turner, L.A. (2003). Data collection strategies in mixed methods research. In A.Tashakkori \& C. Teddlie (Eds.), Handbook of mixed methods in social and behavioral research. Sage Publications. 
Ibrahim, N., \& Nambiar, R. (2011). Writing in foreign lands: The case of postgraduate international students and the introductory sections of a project paper. Procedia - Social and Behavioral Sciences, 18(2011), 626-632.

Kassim, A. (2013). Public universities: Development and internationalisation. In S. Y. Tham (Ed.), Internationalizing higher education in Malaysia:

Understanding, practices and challenges (pp. 41-65). Singapore: Institute of Southeast Asian Studies.

Kaur, S. (2000). Problems in assessing proficiency in English among foreign postgraduate students. Australia: ultiBASE.

Kaur, S., \& Shakila A. M... (2007). The learning experience of postgraduate students: Emergent themes. Bulletin of National Higher Education Research Institute, 9, 26-28.

Kaur, S., \& Sidhu, G.K. (2009). A qualitative study of postgraduate students' learning experiences in Malaysia. International Education Studies, 2(3), 4756.

Kitzinger, J., \& Barbour, R.S. (1999). Introduction: The challenge and promise of focus groups. In R.S. Barbour and J. Kitzinger (eds.), Developing Focus Group Research: Politics, Theory and Practice (pp.1-20). London: Sage.

Kruger, R.A. (1994). Focus groups: A practical guide for applied research $\left(2^{\text {nd }}\right.$ Ed.). Thousand Oaks, CA: Sage.

Krueger, R.A. (1998). Developing Questions for Focus Groups. Thousand Oaks, CA: Sage.

Kruger, R.A., \& Casey, M.A. (2000). Focus groups: A practical guide for applied research. Thousand Oaks, CA: Sage.

Lave, J., \& Wenger, E. (1991). Situated learning: Legitimate Peripheral Participation. Cambridge: Cambridge University Press.

Lavelle, E., \& Bushrow, K. (2007). Writing approaches of graduate students. Educational Psychology, 27 (6), 807-822. Doi: 10.1080/01443410701366001

Lea, M., \& Street, B. (1998). Student writing in higher education: An academic literacies approach. Studies in Higher Education, 23(2), 157-172.

Lea, M.R., \& Street, B.V. (2000). Student writing and staff feedback in higher education: An academic literacies approach. In M.R. Lea \& B. Stierer (Eds.), Student writing in higher education (pp.32-46). London: SRHE: Open University Press.

Lea, M.R., \& Street, B.V. (2006). The “Academic Literacies” Model: Theory and Applications. Theory Into Practice, 45(4), 368-377.

Leki, I. (2001). A narrow thinking system: non-native-English-speaking students in group projects across the curriculum. TESOL Quarterly, 35, 39-67.

Leki, I., \& Carson, J.G. (1994). Students’ perceptions of EAP writing instruction and writing needs across the disciplines. TESOL Quarterly, 28(1), 81-100.

Lillis, T.M., \& Scott, M. (2007). Defining academic literacies research: issues of epistemology, ideology and strategy. Journal of Applied Linguistics, 4(1), 532.

McCallister, C. 2004. Writing education practices within the reconceptualized curriculum. InCritical thinking and learning: An encyclopedia for parents and teachers, ed. J. L. Kincheloe and D. Weil, 144-48. Westport, CT: Greenwood Press.

Miles, M.B. and Huberman, A.M. (1994). Qualitative data analysis: An 
expanded sourcebook. Beverly Hills, CA: Sage.

Morgan, D.L. (1988). Focus groups as qualitative research. Newbury Park, CA: Sage.

Mullen, C. (2006). Best writing practices for graduate students: reducing the discomfort of the blank screen. Kappa Delta Pi Record, 43(1), 30-35.

Norton, B., \& Starfield, S. (1997). Covert language assessment in academic writing. Language Testing, 14(3), 278-294.

Pandian, A., Baboo, S. B. \& Mahfoodh, O. H. A. (2016). Influence of multiculturalism on the study programs in Malaysian public universities: International students' perceptions. Studies in Higher Education, 41(7), 11331152. http://dx.doi.org/10.1080/03075079.2014.968538

Patton, M.Q. (2008). Qualitative research and evaluation methods. Newbury Park, CA: Sage.

Preece, S. (2010). The positioning of learners and educators in discourses associated with academic literacy. In G. Blue (Ed.), Developing academic literacy (pp. 25-38). Bern: Peter Lang.

Prior, P.A. (1994). Response, revision, disciplinary. A microhistory of a dissertation prospectus in sociology. Written Communication, 11(4), 483533.

Rubin, A., \& Babbie, E.R. (2009). Essential Research Methods for Social Work. Cengage Learning. 150.

Ruggles, T.M. (2012). masters level graduate student writing groups: Exploring academic identity. Unpublished Thesis, Arizona State University.

Ryan, J. (2000). A guide to teaching international students. Oxford: Oxford Centre for Staff and Learning Development.

Spradley, J.P., \& McCurdy, D.W. (1972). The cultural experience: Ethnography in complex society. Chicago: Science Research Associates.

Starfield, S. (2007). New directions in student academic writing. In J. Cummins \& C. Davison (Eds.), International handbook of English language teaching (pp. 875-889). New York: Springer.

Singh, M. K. (2015). International graduate students' academic writing practices in

Malaysia: Challenges and solutions. Journal of International Student, 5(1), 12-22.

Singh, M. K. (2016). An emic perspective on academic writing difficulties among international graduate students in Malaysia. GEMA Online: Journal of Language Studies, 16 (3), 83-97.

Singleton-Jackson, J., \& Lumsden, D. (2009). Johnny still can't write, even if he goes to college: a study of writing proficiency in higher education graduate students. Current Issues in Education, 12(10), 1-39.

Siti, S.A., \& Hamidah, S. (2014). Academic adaptation: The experience of malay muslim postgraduate students. Jurnal Pendidikan Malaysia, 39(1), 69-75.

Stewart, D.W., \& Shandasani, P.N. (1990). Focus groups: Theory and practice. Newbury Park, CA: Sage.

Stewart, D. W., \& Spille, H.A. (1988). Diploma mills: Degrees of fraud. New York: American Council on Education and Macmillan.

Street, B.V. (1984). Literacy in theory and practice. Cambridge: CUP.

Swales, J. M. (1990). Genre analysis: English in academic research settings. NY: Cambridge University Press. 
Tran, L. T. (2008). Mutual adaptation of international students and academics for the sustainable development of international education. Retrieved from http://ro.ecu.edu.au/ceducom/58

Tran, L.T. (2013). International student adaptation to academic writing in higher education. UK: Cambridge Scholar Publishing.

Thomas, P. L. (2005). Teaching writing primer. New York: Peter Lang.

VanderStoep, S.W., \& Johnston, D.D. (2009). Research methods for everyday Life. San Francisco: John Wiley \& Sons, Inc.

Wasley, P. (2008). Portfolios are replacing qualifying exams as a step on the road to dissertations. Chronicle of Higher Education, 54(44), A8-A8.

Wong, J. K. (2004). Are the learning styles of Asian internationals culturally or contextually based? International Education Journal, 4(4), 154-166.

Young, T. J. \& Schartner, A. (2014). The effects of cross-cultural communication education on international students' adjustment and adaptation. Journal of Multilingual and Multicultural Development, 35(6), 547-562. http://dx.doi.org/10.1080/01434632.2014.884099

Yuchun, Z. (2010). Understanding of international graduate students' academic adaptation to a u.s. graduate school. Unpublished Thesis, Bowling Green State University.

Yusoff, Y. M. (2012). Self-efficacy, perceived social support, and psychological adjustment in international undergraduate students in a public higher education institution in Malaysia. Journal of Studies in International Education, 16(4), 353-371. http://dx.doi.org/10.1177/1028315311408914

MANJET KAUR MEHAR SINGH, PhD, is a Senior Lecturer in the School of Languages, Literacies and Translation, Universiti Sains Malaysia where she has been a faculty member since 1996. Manjet Kaur completed her PhD, Master and undergraduate studies at Universiti Sains Malaysia. Her major research interests lie in the area of academic literacies, academic integrity, higher education research and multiculturalism. She has published outstanding articles widely in her area. Manjet Kaur has served on various conference and workshop program committees at university, national and international level. She also serves as Editorial Board Member of journals at national and international level. One of the journals that she currently serves as the Editorial Board Member is Asian Journal of Teaching and Learning in Higher Education, UKM. Email: manjeet@usm.my; kmanjet@gmail.com 